\title{
Protein and Overtraining: Potential Applications for Free-Living Athletes
}

\author{
Lonnie Lowery $^{1}$ and Cassandra E Forsythe ${ }^{2}$ \\ University of Akron, Akron, $\mathrm{OH}^{1}$; University of Connecticut, Storrs, $\mathrm{CT}^{2}$. Address correspondence to \\ LL22@uakron.edu
}

Received November 11, 2005/Accepted April 19, 2006

\begin{abstract}
Despite a more than adequate protein intake in the general population, athletes have special needs and situations that bring it to the forefront. Overtraining is one example. Hard-training athletes are different from sedentary persons from the sub-cellular to whole-organism level. Moreover, competitive, "free-living" (less-monitored) athletes often encounter negative energy balance, sub-optimal dietary variety, injuries, endocrine exacerbations and immune depression. These factors, coupled with "two-a-day" practices and in-season demands require that protein not be dismissed as automatically adequate or worse, deleterious to health. When applying research to practice settings, one should consider methodological aspects such as population specificity and control variables such as energy balance. This review will address data pertinent to the topic of athletic protein needs, particularly from a standpoint of overtraining and soft tissue recovery. Research-driven strategies for adjusting nutrition and exercise assessments will be offered for consideration. Potentially helpful nutrition interventions for preventing and treating training complications will also be presented. Journal of the International Society of Sports Nutrition. 3(1):42-50, 2006
\end{abstract}

Key words: Dietary protein, amino acids, overtraining, energy balance, nutrition counseling

\section{INTRODUCTION}

Dietary protein perhaps more than any other nutrient has been historically celebrated and condemned in the realm of sports nutrition. Discrepancies in opinion/ conclusion are affected by population specificity and variables ranging from total kilocalorie (kcal) intake, to injury, to training status, to dietary protein choice(s). The multiple roles of dietary protein and key amino acids such as leucine and glutamine create a variety of potential applications for hard-training athletes. These applications extend beyond acute ergogenesis or body composition improvements which are unlikely and often negative in the literature ${ }^{1-4}$. Dietary protein and select amino acids may be important for athletes during negative energy balance, injuries that do not preclude participation, endocrine exacerbations common to staleness and competition, and immune suppression. Among these interrelated factors, inadequacy of dietary intake may be paramount. An assumption of adequate protein intake during a nutrition assessment should not be made considering suboptimal caloric quantity and quality which are common among athletes and known to elevate protein needs ${ }^{5-7}$. Indeed, it has been stated that: "Although most endurance athletes get enough protein to support any increased requirements, those with low energy or carbohydrate intakes may require nutritional advice to optimize dietary protein intake ${ }^{5}$.

" This paper will explore the unique and multifaceted nature of free-living, under-recovered athletes, and how the stresses they encounter may affect protein needs.

\section{ENERGY BALANCE}

The physical adaptations and stressors of free-living athletes make their energy needs for weight maintenance and normal physiological function substantially different from a "healthy" sedentary person or those in controlled research settings. Both structural and functional tissues are demonstrably modified within weeks, and even days, of training, and these changes are known to increase energy requirements. For example, increased fat-free mass carries a greater energy demand than fat mass. Although the effect on energy expenditure may be lower than once thought at $13 \mathrm{kcal} \cdot \mathrm{kg}^{-1}$ muscle mass ${ }^{8}$, additional kilograms that are specifically lean tissue 
are not accounted for in energy estimate calculations, such as the common Harris Benedict equation. In addition, body composition assessments to calculate resting metabolic rate, such as hydrodensitometry and dual energy x-ray absorptiometry, have been reported to underestimate fat-free mass ${ }^{9}$. Hence in sports nutrition practice settings, a misunderstanding of the energy demands of exercise and accompanying structural alterations could compromise energy balance and weight maintenance.

Despite elevated energy requirements of frequent training and increased lean mass, research indicates that the majority of athletes fail to eat enough calories to maintain energy balance ${ }^{6,10,11}$. Initiating large energy expenditure by athletes does not necessarily induce a compensatory increase in food consumption 12. Possible reasons for poor intakes could include ignorance, lack of appetite, lax dietary habits or conversely, misguided dietary discipline. An important consideration in counseling athletes is their mindset towards nutrition compared to non-athletes. Beyond merely focusing on a small number of food items that are perceived as "healthy", some athletes also suffer true eating disorders. Disordered eating has been reported by $21-48 \%$ of NCAA programs with cross country, track and gymnastics teams ${ }^{13}$. When combined with the additional muscle mass that is characteristic of athletes and higher intensityvolume mesocycles, purposefully restricted intake can become problematic.

\section{PROTEIN NEEDS FOR FREE-LIVING ATHLETES}

In support of physical adaptations and biological demands, protein requirements have been estimated for healthy, eucaloric endurance athletes at 1.2-1.4 $\mathrm{g} / \mathrm{kg} \cdot \mathrm{d}^{-1}$ and slightly more (up to $1.7 \mathrm{~g} / \mathrm{kg} \cdot \mathrm{d}^{-1}$ ) for resistance training athletes ${ }^{5,14}$. Increased protein needs remains controversial and conclusions depend upon initial training status and research methodology. For example, recent isotopic data from McMaster University (Del Bel, et al., 2005; Ontario Exercise Physiology Conference) suggest lower rather than higher protein requirements in adapted resistance trainers consuming ample energy. Whether the enhanced protein robustness is related to the classical "armor plating effect" (e.g. reduced damage response to repeat bouts) or is simply related to a tightlycontrolled, facilitative energy balance is not known. Adequate energy intake is an important control variable in such research, given that a negative energy state is known to elevate protein requirements 5,7 . Indeed, escalating energy intakes do result in escalating nitrogen accretion ${ }^{15}$, but achieving a healthy, large energy surplus is not a simple practice among free-living athletes who engage in more than just controlled exercise training ${ }^{6,11}$.

A goal of many athletes is the acquisition of new and/or "restructured" muscle mass, but protein synthesis is an energy-costly process. It has been estimated that a $2300-3500 \mathrm{kcal}$ surplus is required to build each pound of new muscle tissue ${ }^{4}$. It remains to be settled, however, which macronutrient combination is optimal in supplying this surplus energy. For example, for free-living athletes who regularly experience muscle microtrauma, which is known to interfere with insulin action and glycogen resynthesis ${ }^{16}$, one might question a high $(70 \%$ of kcal or more) carbohydrate diet. The amino acid leucine presents a possible, partial alternative to carbohydrate during ongoing microtrauma, as leucine has been shown to stimulate aspects of the insulin signaling pathway ${ }^{17,18}$ and can itself be oxidized in skeletal muscle ${ }^{5}$. Also supportive of amino acids as a partial alternative to carbohydrate is the ability of glutamine to donate its carbons to glycogen ${ }^{19}$. Although intriguing, the efficacy of glutamine for practical glycogen replenishment remains to be elucidated. Finally, regarding complete proteins, Brodsky and colleagues ${ }^{20}$ reported improved muscle protein anabolism with an ample protein intake versus a minimal one during eucaloric comparisons. Specifically, these investigators noticed higher fractional synthetic rate of myosin heavy chain of the vastus lateralis comparing protein intakes of 1.67 $\mathrm{g} / \mathrm{kg} \cdot \mathrm{d}^{-1}$ compared to minimal $0.71 \mathrm{~g} / \mathrm{kg} \cdot \mathrm{d}^{-1}$.

\section{PROTEIN TIMING AND TOTAL DAILY PROTEIN INTAKE}

Aside from energy balance, another potential difference between some existing research and the apparently persistent affinity of free-living athletes for protein could be the timing of protein ingestion ${ }^{14}$. Data clearly indicate that dietary protein or essential amino acid mixtures enhance net protein balance preand post-resistance exercise ${ }^{3,21,22}$. Properly timed protein intake, particularly when accompanied by additional leucine, can enhance protein balance more than carbohydrate alone ${ }^{22}$. Recent reports describe how branched-chain amino acids (BCAA) and leucine in particular are likely to act acutely via intracellular signaling pathways that support the initiation of protein synthesis. When BCAA are administered during and after resistance exercise, phosphorylation of the mammalian target of rapamycin (mTOR) leads to a sequence of (anabolic) 
enzymatic activations that are not seen to equal extent when BCAA are withheld ${ }^{23}$. It should be noted also that the type of prior training affects the type of intracellular adaptive response under nonsupplemented conditions ${ }^{24}$. Nonetheless humans under different stimuli - that is endurance and resistance exercise - exhibit an increase in protein balance when BCAA/ protein are administered within approximately two hours post-exercise ${ }^{23}$. Further, the observance of leucine's particular anabolic effect may also be related to the otherwise falling concentrations of this amino acid in serum during training $^{2}$.

Athletes who frequently consume (or over-consume) protein may actually be coincidentally fulfilling preand post-exercise windows of opportunity. Considering the absence of any consensus that dietary protein is harmful to the long-term health of non-diseased athletes, moderately over-consumed protein would be less detrimental than underconsumed protein. As examples, Luscombe-Marsh and colleagues ${ }^{25}$ reported no change in calcium excretion, bone turnover, or inflammation among subjects ingesting a $34 \%$ protein diet; Wrone et al 26 reported that protein intake was not related to microalbuminuria in non-diabetic, non-hypertensive persons.

However, in situations of clearly overzealous protein intake (perhaps greater than $2.2 \mathrm{~g} / \mathrm{kg}$ per day) or in the case of excessive supplementation versus whole foods, education on potential negatives is warranted. Aside from simple waste (deamination and increased urinary nitrogen excretion) athlete-specific issues can occur. As reviewed by Gleeson and Bishop ${ }^{6}$, a protein-rich intake ( $24 \%$ of kcal) during four days of very low carbohydrate intake (3\% of kcal) can ironically depress muscle and plasma glutamine by $25 \%$. Hence, a severe devaluation of dietary carbohydrate intake in favor of protein could impact immune function and muscle metabolism. Moreover, Hiscock, et al ${ }^{27}$ reported that glutamine and glutamine-rich protein supplementation increase interleukin-6 in the plasma of subjects during long duration, relatively intense cycling (two hours at $75 \%$ $\mathrm{VO}_{2}$ peak). Although described as an enhancement, this elevation in catabolic, pro-inflammatory interleukin-6 could be viewed as a negative if experienced too frequently. It is currently not clear whether the reported anti-catabolic effects of glutamine ${ }^{27}$ would ultimately outweigh any negative impact of the cytokine. In summary, in situations where very large amounts of dietary protein are being consumed or during training cycles that do not strain an athlete's capacity, counseling on well-timed protein intake can be an alternative to large overall amounts or single amino acid preparations.

\section{ATHLETIC INJURY}

Athletes experience a variety of injuries such as muscle microtrauma (principally due to eccentric contractions), soft tissue and skeletal insults, and surgery. Athletic injuries are common, occur among groups of stale athletes, and are not always met with adequate time away from the exercise regime ${ }^{28,29}$. Galambos, et al. ${ }^{29}$ recently reported that $67 \%$ of athletes at the Queensland Academy of Sport are injured annually, while $18 \%$ were injured at the time of their investigation. Among NCAA Division I football players, approximately one in 20 "exposures" (practices and games) result in injuries 28 . And fully $77.5 \%$ of these injuries are the "nontime-loss" type ${ }^{28}$, meaning that the athletes could experience higher energy and protein needs from the injury (-ies) in addition to training demands.

The least severe form of exercise-induced injury is muscle microtrauma with delayed onset muscle soreness. Albeit purposeful, microtrauma exhibits metabolic characteristics similar to clinical trauma but presents a briefer alteration. Energy needs are increased up to 48 hours ${ }^{30,31}$ while relative insulin insensitivity interferes with optimal use of needed carbohydrate kilocalories ${ }^{16}$. Increased fat oxidation among both clinically injured persons and eccentrically exercised subjects further suggests a shift away from overall carbohydrate metabolism 30,32 . The metabolic coordination of events leading to reduced carbohydrate oxidation may be an attempt by the body to deal with (muscle) insulin resistance and spare diminishing glycogen reserves.

Beyond microtrauma, athletes endure soft tissue injuries and skeletal injuries, which could increase energy and protein needs further. As general examples, minor surgeries increase basal metabolic rate (BMR) by $24 \%$ while skeletal trauma has been reported to increase BMR $32 \%{ }^{33}$. A fracture of a long bone can also induce a decrease in carbohydrate oxidation that only slowly recovers over three weeks 32. Additionally, protein-specific needs have been long-known to increase during injury, as evidenced by urinary nitrogen loss ${ }^{33}$. Such nitrogen catabolism is of particular concern due to the increased contribution of muscle tissue to whole body protein breakdown seen in skeletal trauma ${ }^{34}$. While not all recovering athletes resume full-time training status, it is common knowledge that many resume exercise by 
means of altered exercise regimes. Hence, a combination of elevated metabolic rate, aberrations in skeletal muscle metabolism, and resumed exercise sessions could create a negative energy balance that leads to higher protein needs.

\section{ATHLETIC PERFORMANCE}

Another example in which athletic discipline could "backfire" is training load. This is true from both the coach's and the athlete's perspective. Ongoing twicedaily (or even prolonged and intense once-daily) practices do not allow for adequate recovery. This can be illustrated by the necessary time course for multiple variables to return to baseline values ${ }^{35}$, or by reduced performance and/or fatigue ${ }^{36}$. When uncorrected, overtraining can ensue.

Dietary protein and select amino acids present possible corrective measures against the effects of overtraining and underperformance. The addition of protein to a moderate-carbohydrate meal has been reported to improve glycogen synthetic rate and enhance exercise performance after an initial exercise bout, when compared to a moderate-carbohydrate meal alone ${ }^{37,38}$. Branched-chain amino acids, although often ineffective during acute performance tests ${ }^{4}$, have been reported to reduce visceral fat while maintaining performance among in-training athletes experiencing a moderately negative energy balance ${ }^{2}$. Amino acid supplementation has been shown to reduce decrements in bench press and squat performance during overreaching ${ }^{39}$. Further, the amino acid glutamine serves multiple roles of interest to athletes such as growth hormone secretion, collagen formation, and renal acid excretion ${ }^{40-43}$ but also declines in serum (and muscle) during training and overtraining ${ }^{44}$.

\section{ENDOCRINE AND PHYSIOLOGICAL STRESS}

A stale or overtrained state can be accompanied by a reduced sex hormone:cortisol ratio and elevated catecholamines, depending on the type of overtraining 45-48. Although not always present, hypercortisolemia relative to baseline could be problematic and is not limited to overtraining and poor performance. Competing soccer players have exhibited higher cortisol concentrations during a season, simultaneously with declining glutamine concentrations ${ }^{49}$. Professional cyclists can exhibit relative hypercortisolemia unrelated to performance 47. Yet concerns over increased stress hormones reach beyond performance. Cortisol is not only a catabolic hormone but elevates metabolic rate ${ }^{50}$.
Catabolic and hyper-metabolic effects would have longer-term consequences, affecting body composition and immune status over time, rather than short-term performance. Thus, the overtrained or mid-season endocrine profile suggests catabolism and further-elevated energy and protein needs. Although meals and protein-rich diets increase cortisol concentrations relative to fasting or carbohydrate-rich diets ${ }^{51,52}$, exercise changes this scenario ${ }^{51}$. Contrary to sedentary settings, select amino acids and proteins may actually counteract the elevation and/or catabolic effects of exercise-induced cortisol, as well as improve sleep ${ }^{53-55}$.

Psychological stress and sleep debt are parts of many competitive athletes' lives. Intense, frequent preseason practices and in-season practices, coupled with ongoing competitions, add an additional element of emotional and neuro-endocrine stress beyond that seen in controlled research settings. Emotional stress and sleep quality are not typically addressed in studies of protein requirements but are known to interfere with carbohydrate metabolism and could raise energy expenditure.

\section{IMMUNE AND ANTIOXIDANT DEFENSES}

The immune system plays an important role in physical recovery from exercise, being a necessary part of the tissue repair process ${ }^{35}$. Leukocytosis and cytokine elevations are stimulated during a variety of exercise types ${ }^{35,56}$. However, an elevated white cell count can be severe enough to temporarily stimulate sepsis and at least some of its accompanying inflammatory catabolic cytokines (particularly interleukin-6) ${ }^{56}$. Routinely elevated interleukin-6 is not likely to facilitate maintained muscle mass. Hence, repeated immune stimulation via exercise can be both helpful and detrimental to the goals of an athlete, depending on the magnitude and frequency of its response. Chronic immune system depression is detrimental and becomes apparent relatively quickly during times of overtraining ${ }^{57}$, and during intentional weight reduction undertaken in pursuit of a weight class, such as in judo ${ }^{58}$.

Dietary protein plays a known role in immune system maintenance. When considering the additional immunological stress of athletes, this importance could be increased. Hence, both total protein intake and specific amino acids or protein choices deserve consideration. Moldawer estimated that sustained neutrophilia (neutrophils normally comprising about $60 \%$ of the white cell count) can require 30 grams of protein daily, based upon the total increase in cell 
number and their half-life (American Dietetic Association annual meeting, 1995). Although interorgan exchange of amino acids can supply this, dietary protein may play a role in supplying a portion, sparing muscle tissue. Additionally, white cells oxidize the amino acid glutamine as fuel at a time when muscle and serum concentrations of glutamine fall from exercise and ongoing training 4449,59. A glutamine "tug-of-war" then results that could leave both skeletal muscle and the immune system under-supplied. According to Wilmore and Shabert ${ }^{60}$ : "During inflammatory states, glutamine consumption may outstrip endogenous production and a relative glutamine deficiency state may exist." Wischmeyer and colleagues ${ }^{61}$ have reported that glutamine increases heat shock protein expression and decreases inflammatory cytokines in vitro and in vivo. Recent rodent data involving exercise does suggest increased neutrophil survival and function after high-dose glutamine supplementation ${ }^{62}$. Glutamine has also been reported to decrease upper respiratory tact infections and increase nasal immunoglobulin-A (Ig-A) ${ }^{63,64}$, although it does not apparently elevate salivary Ig-A or affect leukocyte subsets ${ }^{11,64}$. Lastly, bioactive peptides in milk proteins may also provide immune support as they have been shown to be anti-microbial, while potentially enhancing tissue growth ${ }^{65}$.

Immune defenses are not the only defenses deserving consideration during training. Maintained antioxidant capability may also require dietary support. The multiple types of oxidative stress experienced by athletes arguably place them at greater risk than nonathletes. Pro-oxidative processes in athletes, from mitochondrial processing, to leukocytic activity, to reperfusion "injury" are examples of elevated oxidative stress ${ }^{66}$. As with immune stimulation, production of free radicals in the body is beneficial but only when over-stimulation is avoided. Pederson and Hoffman 57 have suggested that proinflammatory cytokines increase the risk of lymphocyte damage via reactive oxygen species. Elevated oxidative stress appears to have a dietary link; both total protein intake and the type of protein or amino acid intake matter. Recent research comparing a minimal protein intake of $0.75 \mathrm{~g} / \mathrm{kg} \cdot \mathrm{d}^{-1}$ with the "habitual" intake of $1.13 \mathrm{~g} / \mathrm{kg} \cdot \mathrm{d}^{-1}$ resulted in decreased erythrocyte glutathione concentrations and kinetics among non-athletes ${ }^{67}$. The authors suggested "increased susceptibility to oxidant stress", a situation that could be made more severe among athletes. Regarding protein type, whey protein has been shown to mitigate a training-induced decline in monocyte and whole-blood glutathione concentrations ${ }^{68}$. Regarding amino acids, Rutten et al. ${ }^{69}$ recently reported a high correlation between muscle glutamate concentrations and muscle glutathione concentration. Further, these authors stated that nutritional supplementation with the glutamate precursors, glutamine, ornithine-alphaketoglutarate or BCAA can influence muscle glutamate status.

\section{CONCLUSION}

The requirements of a competitive season, both physical and psychological, create a unique and under-addressed scenario regarding dietary protein. Indeed, the variety of stresses faced by competing athletes may make them inappropriate recipients of some protein research. Negative energy balance, for example, is purposefully avoided in most studies on protein requirements yet is common to free-living athletes 6,11. This state of "involuntary dieting" increases protein needs and can result from more than simply the reduced appetite accompanying an overreached state. The gross energy demands of two-aday team practices coupled with concomitant resistance training, the hypermetabolism of routine muscle microtrauma ${ }^{30,31}$, the elevated energy needs of accidental injury during practices ${ }^{33}$, stress hormone elevations (i.e. cortisol and catecholamines) 46,48,50, cytokine elevations (e.g. interleukin-6) and related immune stress ${ }^{57,70}$, and sleep disturbances ${ }^{46,71}$ all contribute in an inter-related fashion. Although carbohydrate can and should supply much of the needed $\mathrm{kcal}$, its metabolism can be hampered by many of these factors. Hence, the oftenrecommended $70 \%$ carbohydrate diet (by kcal) appears excessive in many cases. Dietary protein then returns to the forefront of nutritional support for athlete client and patients.

Additionally, amino acids such as glutamine and leucine continue to find acute and indirect research support for the stresses and goals of athletes. Although it is premature to form a consensus on their value due to the methodological constraints of shortterm research ${ }^{3,57}$, the "safe pharmacologic profile" of glutamine ${ }^{55}$ and the "strong theoretical basis ... for expecting a beneficial effect of a protein supplement in active people ${ }^{3}$ " suggests a case-by-case application be considered. Whether the application would be additional individual amino acids (or their peptides) or complete proteins such as whey and casein, remains at the discretion of the sports nutritionist. In any case, select amino acids and complete proteins are potential tools in the sports nutritionist's "toolbox". 
Suggestions for Practice. Depending on the type of nutrition professional and the sport, athletes can be receptive to sports nutrition and supplementation advice. As such, it could be damaging to counsel an athlete that protein is "overrated" or "risky" or even "typically over-consumed." Higher protein diets are not necessarily high fat diets and there is no consensus that they cause osteoporosis in athletes or damage healthy kidneys. To the contrary, this review describes clear physical and psychological differences among athletes that could put them at greater need than other healthy persons or wellmonitored research subjects. Some potential benefits of dietary protein and amino acids for athletes are listed in Table 1.

Table 1. Summary: Reported functions of proteins and amino acids of interest to free living athletes.

1. Building blocks for structural, contractile, hormonal, immune, enzymatic and other bodily proteins

2. Provision of kcal and contribution to muscle glycogen in a relatively carbohydrate- (insulin-) resistant state during eccentric recovery and sleep debt (complete proteins, Gln)

3. Potentially maintained performance during an otherwise stale state (complete proteins, amino acids)

4. Stimulation of protein synthesis in an otherwise catabolic state (Leu)

5. Provision of oxidative fuel to skeletal muscle (Leu), as well as the gut and white blood cells during immune stress $(\mathrm{Gln})$

6. Elevated antioxidant capacity via glutathione (complete proteins, Gln)

7. Improved collagen synthesis and potentially wound healing (Gln)

8. Increased nasal antibodies and/or decreased incidence of infection (Gln)

9. Provision of concentrated nutrients to often poorly-fed athletes (animal protein foods)

10. Defense against stress hormone exacerbations and sleep debt (Gln, alpha-lactalbumin)

Also, rather than simply considering total daily amounts, protein intake options include peri-exercise timing ${ }^{3,14,21}$, a focus on the functional qualities of milk proteins ${ }^{65,68}$, speed of gastric emptying and bloodstream entry ${ }^{72}$ and particularities of the amino acid profile. For example, whey protein concentrates provide more leucine than sodium caseinates and cow's milk ${ }^{73,74}$. These options may not be known to the athlete-client (or athlete-patient). When coupled with education on the need for well-timed carbohydrate choices, sufficient healthy fat intake and dietary variety, protein options become a critical part of a strategic meal plan.
Lastly, from a wellness perspective, appropriately increased nutrition support for tissue growth and repair is imperative to mental health as well as resumption of training. Psychologically, athletes have been reported to experience difficulty dealing with the physical constraints of injury. According to Woodfin ${ }^{75}$ : "The highly motivated athlete requires special consideration of the psychologic ${ }^{76}$ aspects of coping with injuries or medically-imposed limitations on their activity level." Athletes may also conceal disordered eating or injury while attempting to "run through the pain ${ }^{76}$." Thus, a nutrition professional should be wary not to lose rapport with a proteinsupplementing client by failing to empathize with his reasoning. Suggestions for practice are listed in Table 2.

Table 2. Suggestions regarding protein during sports nutrition counseling

1. Consider that the necessary control variables in research settings may make application to your client inappropriate.

2. Recognize that both timing and total intake matter.

3. Use caution not to fall prey to "protein counter-culture", despite the occasional overzealous athlete. Evidence-based practice requires objectivity.

4. Consider that eccentric muscle trauma and underlying injury(-ies) increase energy demands and could make an apparently adequate kcal intake actually deficient.

5. Remain aware of under-reporting on diet records and lack of dietary compensation to new energy expenditures.

6. Remain cognizant that injuries and eating disorders may be concealed by an athlete.

7. Appreciate that the unique psychological motivators of athletes require a unique counseling perspective. 


\section{REFERENCES}

1. Antonio J, Sanders MS, Kalman D, et al.: The effects of high-dose glutamine ingestion on weightlifting performance. J Strength Cond Res 2002, 16:157-160.

2. Mero A: Leucine supplementation and intensive training. Sports Med 1999, 27:347-358.

3. Wolfe RR: Protein supplements and exercise. Am J Clin Nutr 2000, 72:551S-557S.

4. Williams M: Nutrition for health fitness and sport. In Edited by Boston, MA: McGraw-Hill; 2005:227-228, 478.

5. Tarnopolsky M: Protein requirements for endurance athletes. Nutrition 2004, 20:662-668.

6. Gleeson M, Nicolette B: Modification of immune responses to exercise by carbohydrate, glutamine and anti-oxidant supplements. Immunol Cell Biol 2000, 78:554-561.

7. Butterfield GE: Whole-body protein utilization in humans. Med Sci Sports Exerc 1987, 19:S157-165.

8. McClave SA, Snider HL: Dissecting the energy needs of the body. Curr Opin Clin Nutr Metab Care 2001, 4:143-147.

9. LaForgia J, van der Ploeg GE, Withers RT, et al.: Impact of indexing resting metabolic rate against fat-free mass determined by different body composition models. Eur J Clin Nutr 2004, 58:1132-1141.

10. Burke LM: Energy needs of athletes. Can J Appl Physiol 2001, 26 Suppl:S202-219.

11. Gleeson M, Bishop NC: Special feature for the Olympics: effects of exercise on the immune system: modification of immune responses to exercise by carbohydrate, glutamine and anti-oxidant supplements. Immunol Cell Biol 2000, 78:554-561.

12. Stubbs RJ, Sepp A, Hughes DA, et al.: The effect of graded levels of exercise on energy intake and balance in free-living men, consuming their normal diet. Eur J Clin Nutr 2002, 56:129-140.

13. Dick R: Eating disorders in NCAA athletic programs. Athl Training 1991, 26:136-140.

14. Fielding RA, Parkington J: What are the dietary protein requirements of physically active individuals? New evidence on the effects of exercise on protein utilization during post-exercise recovery. Nutr Clin Care 2002, 5:191-196.

15. Chiang AN, Huang PC: Excess energy and nitrogen balance at protein intakes above the requirement level in young men. Am J Clin Nutr 1988, 48:1015-1022.

16. Del Aguila LF, Krishnan RK, Ulbrecht JS, et al.: Muscle damage impairs insulin stimulation of IRS-1, PI 3-kinase, and Aktkinase in human skeletal muscle. Am J Physiol Endocrinol Metab 2000, 279:E206-212.

17. Layman DK: Role of leucine in protein metabolism during exercise and recovery. Can J Appl Physiol 2002, 27:646-663.

18. Meijer AJ: Amino acids as regulators and components of nonproteinogenic pathways. J Nutr 2003, 133:2057S-2062S.

19. Varnier M, Leese GP, Thompson J, et al.: Stimulatory effect of glutamine on glycogen accumulation in human skeletal muscle. Am J Physiol 1995, 269:E309-315.

20. Brodsky IG, Suzara D, Hornberger TA, et al.: Isoenergetic dietary protein restriction decreases myosin heavy chain IIx fraction and myosin heavy chain production in humans. J Nutr 2004, 134:328-334.

21. Tipton KD, Rasmussen BB, Miller SL, et al.: Timing of amino acid-carbohydrate ingestion alters anabolic response of muscle to resistance exercise. Am J Physiol Endocrinol Metab 2001, 281:E197-206.

22. Koopman R, Wagenmakers AJ, Manders RJ, et al.: Combined ingestion of protein and free leucine with carbohydrate increases postexercise muscle protein synthesis in vivo in male subjects. Am J Physiol Endocrinol Metab 2005, 288:E645-653.

23. Blomstrand E, Eliasson J, Karlsson HK, et al.: Branched-chain amino acids activate key enzymes in protein synthesis after physical exercise. J Nutr 2006, 136:269S-273S.

24. Coffey VG, Zhong Z, Shield A, et al.: Early signaling responses to divergent exercise stimuli in skeletal muscle from well-trained humans. Faseb J 2006, 20:190-192.

25. Luscombe-Marsh ND, Noakes M, Wittert GA, et al.: Carbohydrate-restricted diets high in either monounsaturated fat or protein are equally effective at promoting fat loss and improving blood lipids. Am J Clin Nutr 2005, 81:762-772.

26. Wrone EM, Carnethon MR, Palaniappan L, et al.: Association of dietary protein intake and microalbuminuria in healthy adults: Third National Health and Nutrition Examination Survey. Am J Kidney Dis 2003, 41:580-587.

27. Hiscock N, Petersen EW, Krzywkowski K, et al.: Glutamine supplementation further enhances exercise-induced plasma IL-6. J Appl Physiol 2003, 95:145-148.

28. Powell JW, Dompier TP: Analysis of Injury Rates and Treatment Patterns for Time-Loss and Non-Time-Loss Injuries Among Collegiate Student-Athletes. J Athl Train 2004, 39:56-70.

29. Galambos SA, Terry PC, Moyle GM, et al.: Psychological predictors of injury among elite athletes. Br J Sports Med 2005, 39:351-354; discussion 351-354.

30. Melby C, Scholl C, Edwards G, et al.: Effect of acute resistance exercise on postexercise energy expenditure and resting metabolic rate. J Appl Physiol 1993, 75:1847-1853.

31. Dolezal BA, Potteiger JA, Jacobsen DJ, et al.: Muscle damage and resting metabolic rate after acute resistance exercise with an eccentric overload. Med Sci Sports Exerc 2000, 32:1202-1207.

32. Frayn KN, Little RA, Stoner HB, et al.: Metabolic control in non-septic patients with musculoskeletal injuries. Injury 1984, 16:73-79.

33. Long CL, Schaffel N, Geiger JW, et al.: Metabolic response to injury and illness: estimation of energy and protein needs from indirect calorimetry and nitrogen balance. JPEN J Parenter Enteral Nutr 1979, 3:452-456.

34. Long CL, Birkhahn RH, Geiger JW, et al.: Contribution of skeletal muscle protein in elevated rates of whole body protein catabolism in trauma patients. Am J Clin Nutr 1981, 34:1087-1093.

35. Evans WJ, Cannon JG: The metabolic effects of exercise-induced muscle damage. Exerc Sport Sci Rev 1991, 19:99-125.

36. Kentta G, Hassmen P, Raglin JS: Training practices and overtraining syndrome in Swedish age-group athletes. Int J Sports Med 2001, 22:460-465.

37. Ivy JL, Goforth HW, Jr., Damon BM, et al.: Early postexercise muscle glycogen recovery is enhanced with a carbohydrateprotein supplement. J Appl Physiol 2002, 93:1337-1344.

38. Ivy JL, Res PT, Sprague RC, et al.: Effect of a carbohydrate-protein supplement on endurance performance during exercise of varying intensity. Int J Sport Nutr Exerc Metab 2003, 13:382-395. 
39. Ratamess NA, Kraemer WJ, Volek JS, et al.: The effects of amino acid supplementation on muscular performance during resistance training overreaching. J Strength Cond Res 2003, 17:250-258.

40. Curi R, Lagranha CJ, Doi SQ, et al.: Glutamine-dependent changes in gene expression and protein activity. Cell Biochem Funct 2005, 23:77-84.

41. Karna E, Miltyk W, Wolczynski S, et al.: The potential mechanism for glutamine-induced collagen biosynthesis in cultured human skin fibroblasts. Comp Biochem Physiol B Biochem Mol Biol 2001, 130:23-32.

42. Welbourne T, Claville W, Langford M: An oral glutamine load enhances renal acid secretion and function. Am J Clin Nutr 1998, 67:660-663.

43. Welbourne TC: Increased plasma bicarbonate and growth hormone after an oral glutamine load. Am J Clin Nutr 1995, 61:10581061.

44. Rowbottom DG, Keast D, Morton AR: The emerging role of glutamine as an indicator of exercise stress and overtraining. Sports Med 1996, 21:80-97.

45. Urhausen A, Gabriel H, Kindermann W: Blood hormones as markers of training stress and overtraining. Sports Med 1995, 20:251-276.

46. Hooper SL, Mackinnon LT, Howard A, et al.: Markers for monitoring overtraining and recovery. Med Sci Sports Exerc 1995, 27:106-112.

47. Hoogeveen AR, Zonderland ML: Relationships between testosterone, cortisol and performance in professional cyclists. Int J Sports Med 1996, 17:423-428.

48. Fry AC, Kraemer WJ, Van Borselen F, et al.: Catecholamine responses to short-term high-intensity resistance exercise overtraining. J Appl Physiol 1994, 77:941-946.

49. Filaire E, Lac G, Pequignot JM: Biological, hormonal, and psychological parameters in professional soccer players throughout a competitive season. Percept Mot Skills 2003, 97:1061-1072.

50. Brillon DJ, Zheng B, Campbell RG, et al.: Effect of cortisol on energy expenditure and amino acid metabolism in humans. Am J Physiol 1995, 268:E501-513.

51. Kanaley JA, Weltman JY, Pieper KS, et al.: Cortisol and growth hormone responses to exercise at different times of day. J Clin Endocrinol Metab 2001, 86:2881-2889.

52. Anderson KE, Rosner W, Khan MS, et al.: Diet-hormone interactions: protein/carbohydrate ratio alters reciprocally the plasma levels of testosterone and cortisol and their respective binding globulins in man. Life Sci 1987, 40:1761-1768.

53. Markus CR, Olivier B, Panhuysen GE, et al.: The bovine protein alpha-lactalbumin increases the plasma ratio of tryptophan to the other large neutral amino acids, and in vulnerable subjects raises brain serotonin activity, reduces cortisol concentration, and improves mood under stress. Am J Clin Nutr 2000, 71:1536-1544.

54. Markus CR, Jonkman LM, Lammers JH, et al.: Evening intake of alpha-lactalbumin increases plasma tryptophan availability and improves morning alertness and brain measures of attention. Am J Clin Nutr 2005, 81:1026-1033.

55. Salehian B, Kejriwal K: Glucocorticoid-induced muscle atrophy: mechanisms and therapeutic strategies. Endocr Pract 1999, 5:277-281

56. Ostrowski K, Hermann C, Bangash A, et al.: A trauma-like elevation of plasma cytokines in humans in response to treadmill running. J Physiol 1998, 513 ( Pt 3):889-894.

57. Pedersen BK, Hoffman-Goetz L: Exercise and the immune system: regulation, integration, and adaptation. Physiol Rev 2000, 80:1055-1081.

58. Ohta S, Nakaji S, Suzuki K, et al.: Depressed humoral immunity after weight reduction in competitive judoists. Luminescence 2002, 17:150-157.

59. Miles MP, Naukam RJ, Hackney AC, et al.: Blood leukocyte and glutamine fluctuations after eccentric exercise. Int J Sports Med 1999, 20:322-327.

60. Wilmore DW, Shabert JK: Role of glutamine in immunologic responses. Nutrition 1998, 14:618-626.

61. Wischmeyer PE: Glutamine and heat shock protein expression. Nutrition 2002, 18:225-228.

62. Lagranha CJ, de Lima TM, Senna SM, et al.: The effect of glutamine supplementation on the function of neutrophils from exercised rats. Cell Biochem Funct 2005, 23:101-107.

63. Krieger JW, Crowe M, Blank SE: Chronic glutamine supplementation increases nasal but not salivary IgA during 9 days of interval training. J Appl Physiol 2004, 97:585-591.

64. Castell LM, Poortmans JR, Newsholme EA: Does glutamine have a role in reducing infections in athletes? Eur J Appl Physiol Occup Physiol 1996, 73:488-490.

65. Bos C, Gaudichon C, Tome D: Nutritional and physiological criteria in the assessment of milk protein quality for humans. J Am Coll Nutr 2000, 19:191S-205S.

66. Lowery L: Antioxidants Supplements and Exercise. In Sports Supplements. Edited by Antonio J, Stout J. Philadelphia, PA: Lippincott, Williams and Wilkins; 2001:260-278.

67. Jackson AA, Gibson NR, Lu Y, et al.: Synthesis of erythrocyte glutathione in healthy adults consuming the safe amount of dietary protein. Am J Clin Nutr 2004, 80:101-107.

68. Middleton N, Jelen P, Bell G: Whole blood and mononuclear cell glutathione response to dietary whey protein supplementation in sedentary and trained male human subjects. Int J Food Sci Nutr 2004, 55:131-141.

69. Rutten EP, Engelen MP, Schols AM, et al.: Skeletal muscle glutamate metabolism in health and disease: state of the art. Curr Opin Clin Nutr Metab Care 2005, 8:41-51.

70. Tsigos C, Papanicolaou DA, Defensor R, et al.: Dose effects of recombinant human interleukin-6 on pituitary hormone secretion and energy expenditure. Neuroendocrinology 1997, 66:54-62.

71. Fry RW, Grove JR, Morton AR, et al.: Psychological and immunological correlates of acute overtraining. Br J Sports Med 1994, 28:241-246.

72. Dangin M, Boirie Y, Guillet C, et al.: Influence of the protein digestion rate on protein turnover in young and elderly subjects. J Nutr 2002, 132:3228S-3233S. 
73. Davis TA, Nguyen HV, Garcia-Bravo R, et al.: Amino acid composition of the milk of some mammalian species changes with stage of lactation. Br J Nutr 1994, 72:845-853.

74. Sindayikengera S, Xia WS: Nutritional evaluation of caseins and whey proteins and their hydrolysates from Protamex. J Zhejiang Univ Sci B 2006, 7:90-98.

75. Woodfin BA: Orthopaedic sports medicine and the adult male athlete: a review of common exercise-related injuries. J Med Assoc Ga 1998, 87:17-21.

76. Thomson R, Sherman R: Helping athletes with eating disorders. In Edited by Champaign, IL: Human Kinetics; $1993: 72$. 